\title{
Intensiv lernen und diskutieren auf dem Radiologiekongress Nord
}

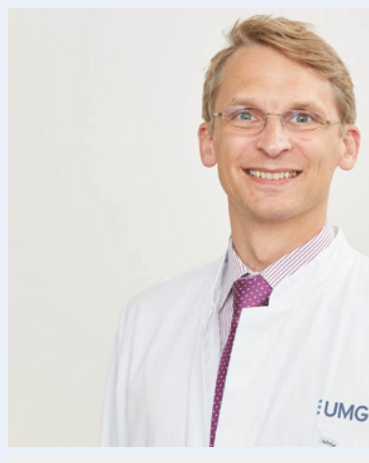

Prof. Dr. Joachim Lotz

Die Kongresspräsidenten Prof. Dr. Joachim Lotz und Prof. Dr. Christian Ritter zum Programm des Radiologiekongresses Nord 2017.

\section{Weshalb sollte man den Radiologiekon- gress Nord 2017 auf keinen Fall verpassen?}

Lotz: Der RöKo Nord 2017 fokussiert ganz auf die Fortbildung. Er soll gesichertes Wissen bieten für den Alltag. Zugleich soll der RöKo Nord 2017 Wissen vermitteln zu Neuentwicklungen, die uns als praktisch tätige Radiologen unmittelbar betreffen werden. Und über das alles hinaus soll er uns norddeutschen Radiologen auch ein Forum für den persönlichen Austausch und anregende Diskussionen sein.

Ritter: Wir führen damit das neue Konzept fort, das von Professor Frank Wacker aus Hannover und Professor Roman Fischbach aus Hamburg initiiert und von PD Dr. Roger Eibel auch 2018 weiter gelebt werden wird.

\section{Es fällt auf, dass bei diesem Kongress ins- besondere die Arbeit in Kleingruppen groß geschrieben wird. Welche Überlegung steht dahinter?}

Ritter: Die Workshops sollen ein intensives Lernen und Diskutieren an Fällen in einer Gruppe von maximal 20 Teilnehmern ermöglichen. Sie sind thematisch stärker fokussiert als die Übersichtsvorträge, sodass man in die Themen tiefer einsteigen kann.

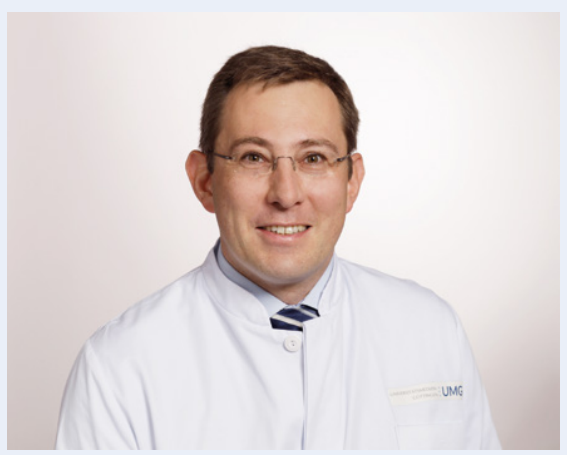

Prof. Dr. Christian Ritter

Lotz: Wir ergänzen die Workshops außerdem noch um einzelne Hands-On-Kurse an Simulatoren - ein neues Format, das wir hier erstmalig anbieten wollen.

\section{Worauf dürfen sich MTRA besonders} freuen?

Lotz: Für die MTRA haben wir ein außergewöhnlich breites Angebot geschaffen: von Hands-On am Gerät bis zu mit exzellenten Referenten bestückten Refresherkursen; mit Themen von der Herzbildgebung bis zur Hygiene und Praxis- / Klinikmanagement. Zusammen mit einer bewusst gering gehaltenen Teilnahmegebühr wollen wir dieses mit viel Detailliebe von Frau Gebel und der VMTB konfigurierte Programm für möglichst viele MTRA attraktiv machen.

Der Digitalisierung in der Medizin widmen Sie besondere Aufmerksamkeit. Über welche Fragestellungen und aktuellen Entwicklungen informiert hier der Radiologiekongress Nord?

Ritter: Digitalisierung, Big Data und Machine Learning sind Schlagworte, die derzeit vielfach zitiert, aber nicht immer verstanden werden. Wir wollen hier gezielt aufklären und informieren - ja, auch ein wenig die Angst nehmen. Wir hoffen so, den Teilnehmern die Chancen für unser Fach darlegen und mit allen zusammen dieses wichtige Thema diskutieren zu können.
Was sind Ihre persönlichen ProgrammHighlights?

Lotz: Für uns beide ist sicherlich die Highlight-Sitzung zum Thema Big Data am Freitag ein Höhepunkt des Kongresses. Spannend werden auch die Kleingruppen-Workshops, Q-Kurse und Strahlenschutzkurse, in die viel Arbeit und Mühe investiert worden ist.

Ritter: Besonders freuen wir uns auch über das Klinische Symposium am Samstagmorgen zur cerebralen Thrombektomie. Es lohnt sich auf jeden Fall, für den 17. und 18. Februar 2017 die Reise nach Göttingen anzutreten.

Vielen Dank für das Gespräch!

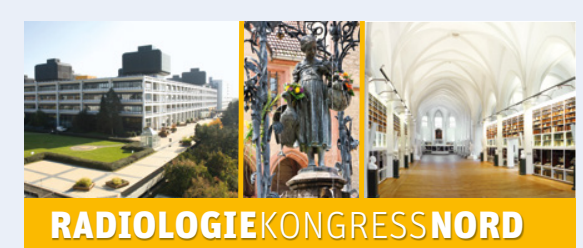

RADIOLOGIEKONGRESSNORD

17.| 18. FEBRUAR 2017]

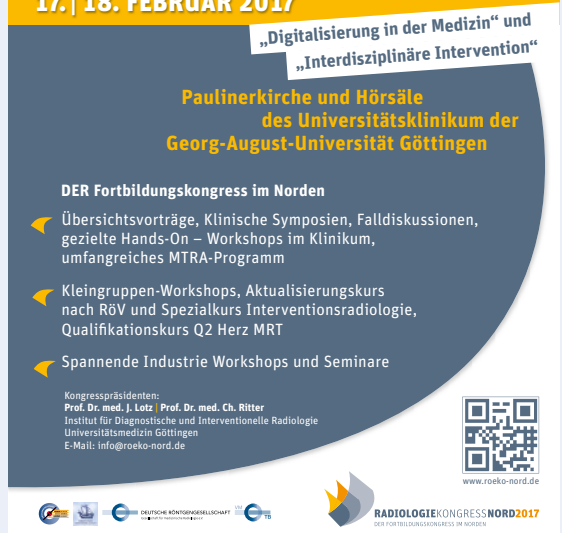

